\title{
ANÁLISE TEMPORAL DO USO DO SOLO ATRAVÉS DE FERRAMENTAS DE GEOPROCESSAMENTO - ESTUDO DE CASO: MUNICÍPIO DE BUTIÁ/RS ${ }^{1}$
}

\author{
Aline Duarte Kaliski ${ }^{2}$ \\ Me. Tânia Rodrigues Ferrer ${ }^{3}$ \\ Prof. Dr. Regis Alexandre Lahm ${ }^{4}$
}

\section{Resumo}

A sociedade atual se depara com inúmeros fatores relacionados ao uso sustentável dos recursos naturais. Diante disso, diversas medidas vêm sendo tomadas por meio de políticas públicas que visam um meio ambiente ecologicamente equilibrado e o desenvolvimento sustentável. Nesse sentido, algumas áreas que são importantes para o equilíbrio dos ecossistemas e do meio ambiente são protegidas por lei, como é caso das Áreas de Preservação Permanentes. Dessa forma, este estudo se propõe a analisar o uso e a ocupação do solo no município de Butiá, Rio Grande do Sul, em determinado espaço temporal, avaliando os diferentes usos do solo, com atenção especial as áreas de preservação permanentes relacionadas aos cursos d'água. A análise será feita por meio do uso de imagens de Sensoriamento Remoto e elaboração de um Sistema de Informação Geográfica.

Palavras Chave: Uso e Ocupação do Solo, Áreas de Preservação Permanente, Sensoriamento Remoto, Sistemas de Informação Geográfica.

\footnotetext{
Abstract

Contemporary society is faced with numerous factors related to the sustainable use of natural resources. For that reason, several measures have been taken through public policies aimed at an ecologically balanced environment and the sustainable development. In this sense, some

${ }^{1}$ Este artigo faz parte de um trabalho maior desenvolvido na monografia de final de curso intitulada Avaliação Temporal do Uso e Ocupação do Solo no Município de Butiá/RS. KALISKI A. Monografia de final de curso, Faculdade de Filosofia e Ciências Humanas, curso de Bacharel em Geografia da Pontifícia Universidade Católica do Rio Grande do Sul (PUC/RS).

${ }^{2}$ Bacharel em Geografia pela PUCRS. <adkaliski@yahoo.com.br>.

${ }^{3}$ Professora do Curso de Geografia da Faculdade de Filosofia e Ciências Humanas, Pontifícia Universidade Católica do Rio Grande do Sul. Porto Alegre, RS. <tania.ferrer@ pucrs.br>.

${ }^{4}$ Doutor em Recursos Hídricos e Saneamento Ambiental. Pontifícia Universidade Católica do Rio Grande do Sul (PUCRS). Porto Alegre, RS.<lahm@pucrs.br>.
} 
areas that are important to the balance of ecosystems and to the environment are protected by law, like the areas near the watercourses. Thus, this study aims to analyze the use and occupation of land in the municipality of Butia, Rio Grande do Sul, in a particular space-time, evaluating the different land uses, with special attention to areas of permanent preservation related to watercourses. The analysis will be done through the use of remote sensing images and the development of a Geographic Information System.

Keywords: Use and occupation of land, Legally protected areas, Remote Sensing, Geographic Information System.

\section{Introdução}

No mundo contemporâneo, analisar a dinamicidade da sociedade no espaço geográfico e as relações que o homem mantém com o mesmo torna-se de extrema importância em estudos de planejamento e monitoramento do espaço, tendo em vista algumas inquietações surgidas nas últimas décadas relacionadas ao uso sustentável dos recursos naturais. Algumas formas de uso e exploração dos recursos naturais podem causar desequilíbrio ecológico gerando degradação do meio ambiente. Fenômenos naturais, como a erosão e a inundação, podem ser potencializados por ações antrópicas. A derrubada de vegetação nativa, por exemplo, pode acelerar os processos erosivos.

A integração de técnicas de sensoriamento remoto e geoprocessamento se dá por meio dos Sistemas de Informações Geográficas (SIG’s), que se configuram em ferramentas capazes de fornecer informações sobre a superfície da Terra, contribuindo para o monitoramento de áreas em diferentes escalas de mapeamento, tanto em nível local, como regional e global. Nesse sentido, a utilização destas geotecnologias vem evoluindo de forma significativa nos últimos anos, abrangendo diferentes organizações nas áreas de administração municipal, infra-estrutura, gestão ambiental, educação, entre outras.

Neste âmbito, a Ciência Geográfica - por estudar os fenômenos naturais e a relação sociedade/natureza no espaço e no tempo, aliada ao uso de geotecnologias - contribui para aprimorar o conhecimento sobre o espaço geográfico. Isso faz com que essa ciência, além de ser mais valorizada, ganhe mais espaço em estudos de planejamento e monitoramento do território.

A partir dessas considerações, propomos realizar uma análise temporal do uso e ocupação do solo no município de Butiá/RS, através de imagens obtidas por sensoriamento remoto. Para isso, tendo em vista a importância da preservação dos recursos naturais, 
sobretudo a manutenção e qualidade das águas, delimitamos as Áreas de Preservação Permanente relacionadas aos cursos d'água, com base na resolução CONAMA nº 303/2002 e na Lei ${ }^{\circ} 4.771$, de 15 de setembro de 1965 do Código Florestal, a fim de verificar se houve preocupação na preservação da vegetação nestes espaços.

\section{Áreas de Preservação Permanente}

Com a necessidade de preservar algumas áreas que contribuem para a sustentabilidade dos recursos naturais, alguns espaços territoriais foram considerados por lei como áreas de preservação ambiental. Nesses espaços, à exceção de casos especiais, deve-se evitar a ocupação ou o uso para atividades que possam acarretar alterações do seu sistema natural. As Áreas de Preservação Permanente (APP's) juntamente com as reservas legais, reservas indígenas e as unidades de conservação, fazem parte do sistema de áreas protegidas da legislação ambiental brasileira.

As APP's demandam atenção especial, pois possuem grande importância na manutenção natural dos ecossistemas. De acordo o Código Florestal Federal Brasileiro (Lei 4.771 de artigo $1^{\circ}, \S 2^{\circ}$, inciso III, de 15/09/1965), denominam-se Áreas de Preservação Permanente:

\footnotetext{
“Áreas cobertas ou não por vegetação nativa, com a função ambiental de preservar os recursos hídricos, a paisagem, a estabilidade geológica, a biodiversidade, o fluxo gênico de fauna e flora, proteger o solo e assegurar o bem-estar das populações humanas". (BRASIL, 1965)
}

Atualmente as APP's são também regulamentadas pela Resolução CONAMA n. ${ }^{\circ}$ 302/2002, que dispõe sobre APP's para reservatórios artificiais e uso do entorno e sobre parâmetros, definições e limites das APP's. Como exemplo de áreas de preservação permanente podem ser citadas as margens dos rios, os arredores de lagoas, lagos ou reservatórios d'água e os topos de morros, montes, montanhas e serras.

Conforme a legislação vigente, as formações florestais e demais formas de vegetação devem ser mantidas em extensões específicas, de acordo com a largura dos diferentes corpos d'água, conforme representado na figura 1. 


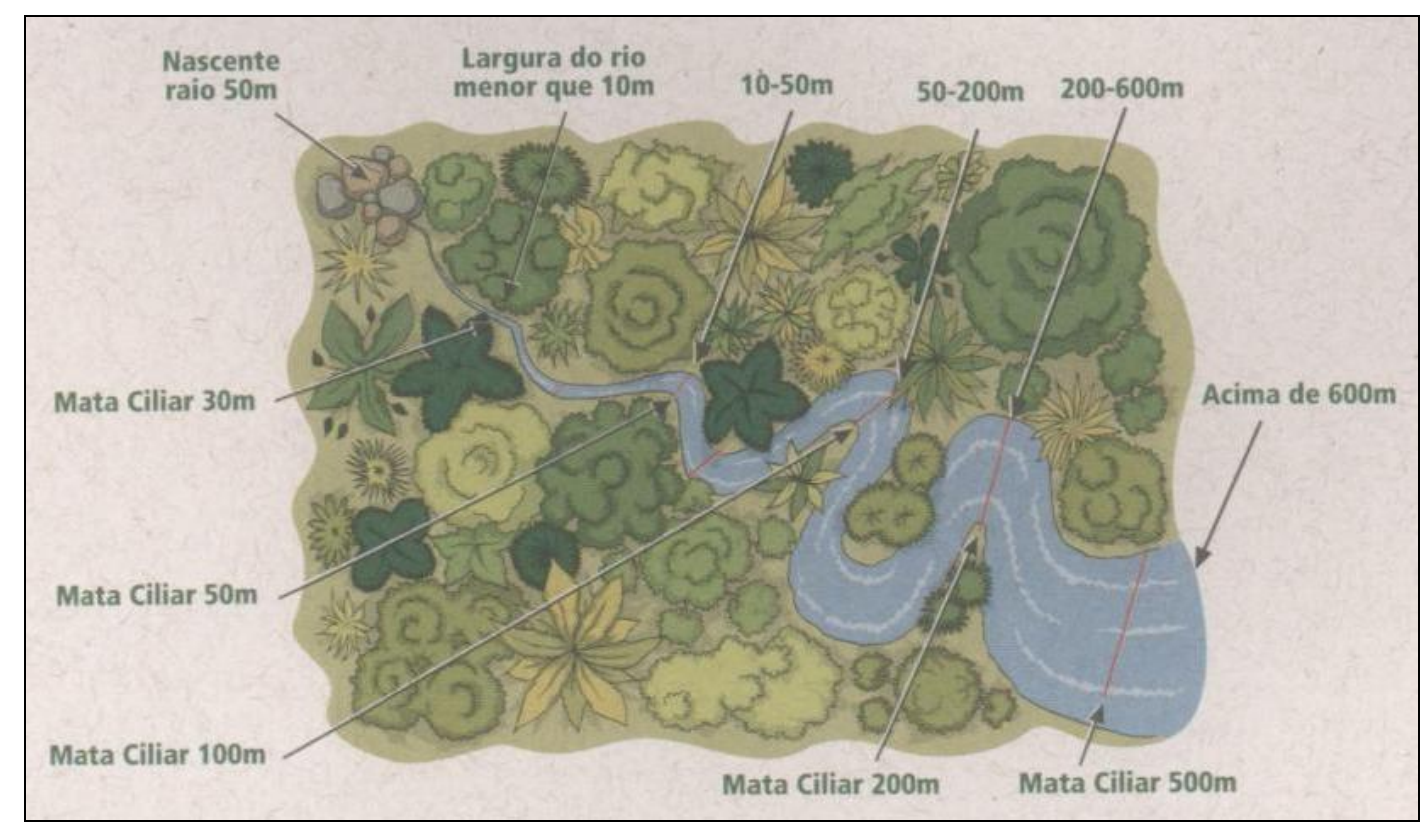

Figura 1 - Extensões específicas de APP's em cursos d'água

Fonte: Secretaria Estadual do Meio Ambiente/RS, 2007.

A conservação e a preservação de vegetação nativa, sobretudo aquelas situadas ao longo de cursos d'água, nascentes, lagos e lagoas, são fundamentais para a proteção dos recursos hídricos. Conforme destaca SEMA (2007), estes espaços sempre foram alvos de grandes impactos, pois o modelo de ocupação territorial, desde a Antiguidade, sempre teve como referencial a proximidade de aglomerados urbanos com os cursos d'água. Isso porque, além dos aspectos referentes ao abastecimento de água, estes espaços proporcionavam a solução mais prática para outras necessidades, como vias de transporte, fonte de alimentação direta (pesca) e indireta (agricultura e pecuária).

Nas últimas décadas, a aceleração do processo de urbanização e o desenvolvimento das atividades econômicas e sociais aliadas aos avanços tecnológicos exerceram considerável mudança na cobertura vegetal, muitas vezes desrespeitando a legislação.

Neste contexto, as informações sobre o uso e ocupação do solo tornam-se de extrema importância na implantação de projetos de planejamento e monitoramento ambiental. Para auxiliar em tais projetos, a integração de técnicas de geoprocessamento e sensoriamento remoto, através dos Sistemas de Informações Geográficas (SIG’s), torna-se uma ferramenta de grande utilidade, pois permite, por meio da análise de imagens de satélites e da modelagem de dados geográficos, a obtenção de informações rápidas e precisas em diferentes escalas de observação do espaço. 


\section{Geoprocessamento, Sistemas de Informações Geográficas e Sensoriamento Remoto}

De acordo com Carvalho (2000), o geoprocessamento é um termo amplo que através de programas computacionais engloba diversas tecnologias de tratamento e manipulação de dados geográficos. Dentre essas tecnologias, destacam-se o sensoriamento remoto, a digitalização de dados, a automação de tarefas cartográficas, a utilização de Sistemas de Posicionamento Global - GPS e os Sistemas de Informações Geográficas - SIG’s.

Moura (2003) acredita que o geoprocessamento representa hoje, um caminho a ser necessariamente percorrido pelos estudos em Geografia e em análises espaciais de qualquer natureza. $\mathrm{O}$ autor ressalta que:

\footnotetext{
O desafio, nos estudos geográficos, está em realizar um corte espaço-temporal para as análises, mas, ao mesmo tempo, não perder a noção de que a realidade é sistêmica e que está em constante mudança. Uma realidade percebida aqui e agora não é mais percebida em um momento seguinte ou em um outro espaço [...] E o sentido nos estudos geográficos está em caracterizar uma realidade espacial de modo a gerar subsídios para estudos de predições: as alterações e as implicações dessas intervenções. Uma metodologia para a realização desses estudos está na construção de modelos que, devidamente calibrados, podem chegar bem próximos da representação da realidade. O desafio é a construção de modelos que espelhem a dinâmica das mudanças, as relações sistêmicas e o papel dos diferentes componentes da teia ou rede de inter-relações. (MOURA, 2003, p. 35)
}

Os recursos de geoprocessamento aparecem como importantes instrumentos que podem proporcionar associações, sínteses e correlações entre as diferentes análises, além de permitir uma visão integrada de fatores geográficos. Neste sentido, o geoprocessamento tem sido empregado em diversas áreas das Ciências, dentre as quais se pode citar a Cartografia, a Geografia, a Agricultura e a Geologia, contribuindo para estudos de planejamento territorial, estudos ambientais, meios de transporte, comunicação e energia. Contudo, é importante salientar que as operações de geoprocessamento necessitam de um sistema de informação geográfica para integração dos dados.

De acordo com Silva (1999), o termo Sistema de Informação Geográfica é aplicado para um conjunto de sistemas computacionais que permitem a associação de dados gráficos (mapas) e não gráficos (tabelas) estruturados em um banco de dados. Os SIG's servem de base para a gestão espacial e, consequentemente, à soluções de problemas de determinadas áreas da superfície terrestre. Além disso, permitem a integração e a interação de dados referenciados espacialmente com vistas a produzir análises espaciais como suporte à tomada de decisão técnica ou política. 
Vários autores vêm empregando análises temporais através de dados obtidos por sensoriamento remoto, a fim de detectar mudanças na paisagem de determinada região. Giotto (1981) ressalta que o monitoramento do uso e cobertura do solo é de grande relevância, pois permite mapear as alterações provocadas por ações antrópicas, além de fornecer informações para o manejo eficiente dos recursos naturais.

Visando contribuir com o planejamento e gestão da Bacia, Bachega et. al. 2009, através de imagens do Sensor TM LANDSAT 5, realizaram uma análise multitemporal da cobertura do solo na bacia do Rio Negro/MS. No período analisado, anos de 1985 e 2007, constataram um aumento das áreas antropizadas e significativa diminuição das áreas cobertas por florestas e cerrados. De acordo com os autores, o desmatamento na Bacia do Rio Negro representa uma ameaça, pois aumenta a chance de erosão no terreno, causando deposição de sedimentos nas depressões e planícies, alterando os padrões de fluxo da água e reduzindo o número de espécies da fauna e flora do local (BACHEGA ET. AL. 2009).

Sampaio (2007) realizou uma análise ambiental de conflitos de uso do solo em áreas de preservação permanente na Bacia Hidrográfica de Vargem das Flores, município de Contagem - Minas Gerais. Nesse estudo, foram analisadas as APP's de cursos d'água e topo de morro processadas em um ambiente de SIG, no qual realizaram-se cruzamentos com o mapa de uso e ocupação do solo gerado a partir da Imagem do satélite LANDSAT-ETM+, cena de 2002. Como resultado, constatou-se que a urbanização na bacia é um fator agravante, pois sua expansão está em conflito direto com os cursos d'água, causando grandes impactos na represa com o comprometimento da qualidade da água devido ao assoreamento e lançamento de esgotos.

\section{Área de Estudo: Características Geográficas}

O Município de Butiá localiza-se a uma latitude $30^{\circ} 07^{\prime} 11^{\prime} \mathrm{S}$ e a uma longitude 51 57'44" W, inserido na micro-região do Vale do Jacuí. Conforme o Instituto Brasileiro de Geografia e Estatística (IBGE), conta com uma área territorial de $769 \mathrm{Km}^{2}$, estando a uma altitude de 71 metros. Sua população em 2007 era de 19.717 habitantes (IBGE, 2009). 


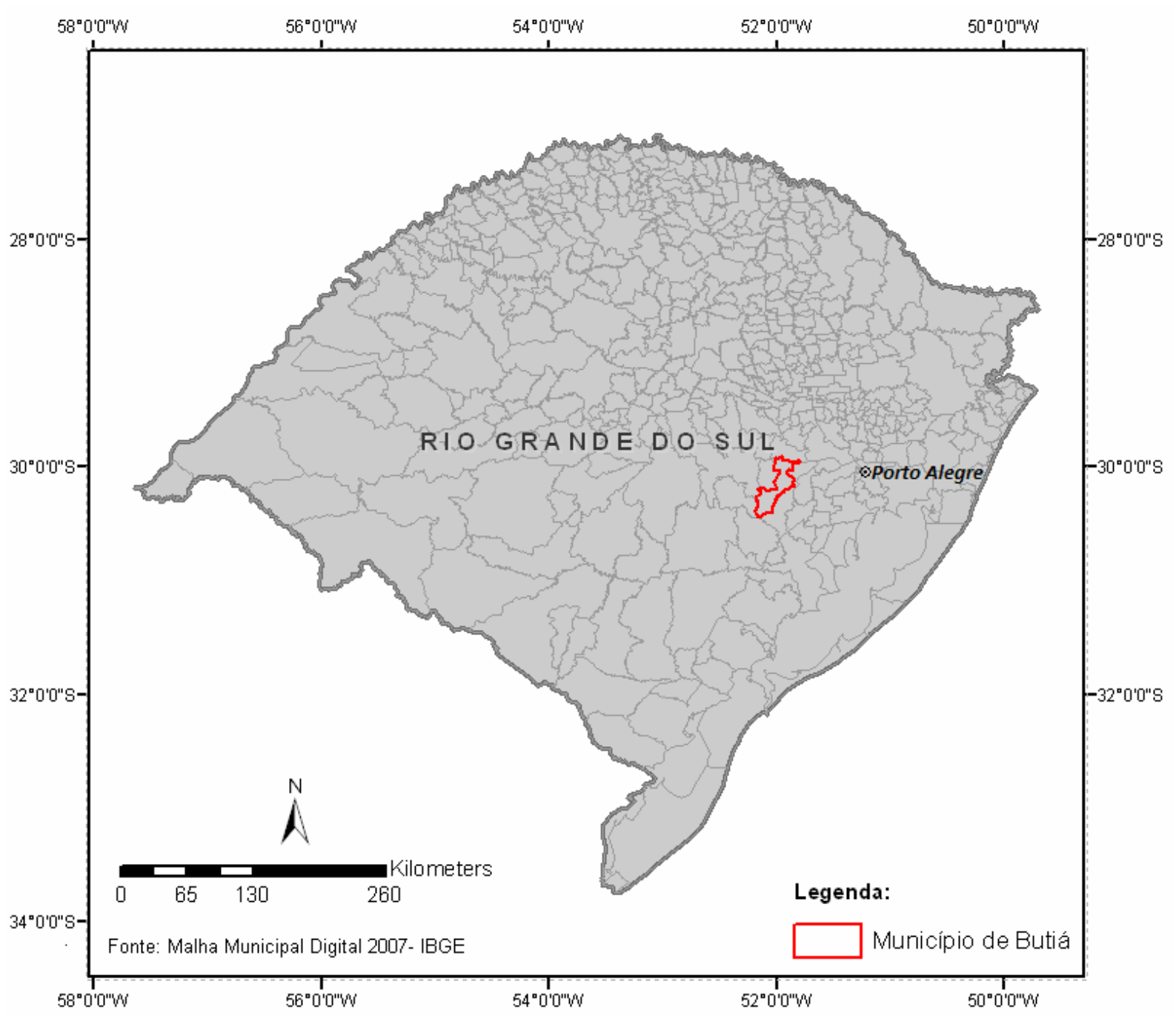

Figura 2: Mapa de Localização do Município de Butiá/RS

Fonte: $\mathrm{O}$ autor

A cidade de Butiá nasceu e se desenvolveu em função do carvão, toda a história da cidade esta ligada a mineração. Outra atividade econômica que se destaca atualmente é a silvicultura. Ambas as atividades podem acarretar impactos ambientais, à medida em que não se respeite a sustentabilidade dos recursos naturais, principalmente em áreas protegidas pela legislação vigente. Assim, o monitoramento do uso e ocupação do solo é de grande relevância, pois fornece informações dos tipos de usos e subsidia ações de planejamento.

\section{Materiais e Métodos:}

A base de dados para a análise do estudo se restringiu a dois formatos: vetorial e raster. Os dados vetoriais referem-se à rede hidrográfica, enquanto o raster às imagens de satélite Landsat 5 TM. 
As imagens de satélite foram fornecidas pelo INPE, correspondentes à órbita/ponto: 221/081 do satélite Landsat 5. A primeira imagem corresponde à data de passagem do satélite em 10/12/1886 e a outra imagem em 07/01/2009.

Os softwares utilizados como suporte nesta pesquisa foram: AutoCad MAP 2007, ArcGis 9.3 e Idrisi Versão 15.0 Andes Edition, além do pacote de aplicativos OFFICE.

Para a obtenção das Áreas de Preservação Permanente adotaram-se os critérios de limites descritos na Resolução CONAMA Nº 303 de 20 de março de 2002, considerando os seguintes incisos:

I - em faixa marginal, medida a partir do nível mais alto, em projeção horizontal, com largura mínima, de:

a) trinta metros, para o curso d'água com menos de dez metros de largura; b) cinqüenta metros, para o curso d'água com dez a cinqüenta metros de largura; c) cem metros, para o curso d'água com cinqüenta a duzentos metros de largura;

II - ao redor de nascente ou olho d'água, ainda que intermitente, com raio mínimo de cinqüenta metros de tal forma que proteja, em cada caso, a bacia hidrográfica contribuinte;

Considerando a resolução espacial da imagem LANDSAT (30metros), adotou-se APP's de 50 metros para os cursos d'água com menos de 10 metros e até 50 metros de largura. Neste caso, as APP's, em grande maioria, restringiram-se a 50m para a maioria dos cursos d'água juntamente com as nascentes. O único curso d'água a apresentar APP de 100 metros foi o Rio Jacuí.

Após a definição dos limites de APP's, no software AutoCad Map 2007, os diferentes tipos de APP's foram separados por layers ou camadas. Dessa forma, pôde-se aplicar o comando buffer nos layers para a demarcação das APP's. Esse comando gerou polígonos paralelos ao redor das linhas e polígonos dos cursos d'água com as distâncias específicas, conforme a Resolução CONAMA e incisos supracitados.

Após a delimitação das APP's no software AutoCad, exportou-se o layer da mesma para o formato DXF (AutoDesk Drawing Interchange), sendo este um arquivo de intercâmbio entre modelos $\mathrm{CAD}$ e outros programas.

No software Idrisi, importou-se o arquivo vetorial denominado “APP.dxf”, tornando-o um arquivo vetorial do software Idrisi (extensão *.vct). Logo, o arquivo vetorial de APP's precisou ser rasterizado, ou seja, transformado para o formato raster. Para obtenção de tal formato, utilizou-se a função raster/vector, disponível no menu Reformat. Assim, resultaram produtos com as demarcações específicas de distâncias das APP's, conforme descrito anteriormente. 
A elaboração dos mapas de uso e ocupação do solo se deu a partir do processamento digital das imagens, sendo necessário o georreferenciamento da mesma, uma vez que estas estão sujeitas a uma série de distorções espaciais. Para a realização deste procedimento foi necessário identificar pontos de controle, facilmente identificáveis na base cartográfica e na imagem. Após o georreferenciamento, a fim de melhorar a interpretação visual das imagens, aplicou-se o realce no contraste da imagem, na qual se ampliou o contraste de feições na cena.

Realizados os procedimentos de pré- processamento das imagens, o próximo passo consistiu na geração de imagens coloridas para facilitar o processo de visualização e classificação ou extração de informações. Com base na interpretação visual, foram definidas cinco classes de uso do solo, descritas a seguir:

Floresta nativa: esta classe compreende as áreas ocupadas por diferentes formações florestais nativas, incluindo as matas ciliares.

Campo, pastagens e culturas anuais: estas classes foram agrupadas por apresentarem o mesmo padrão fisionômico na resolução espacial da imagem adotada, dificultando a separação destas classes sem apoio de dados de campo.

Floresta plantada: áreas ocupadas com plantios de florestas exóticas (Eucalipto e Acácia).

Água: esta classe engloba todos os corpos d'água, rios, açudes e lagos.

Solo exposto/Áreas Construídas: nessa classe foram considerados áreas ocupadas com estradas, sede das propriedades rurais, ocupação do solo com predominância de construções e solo exposto.

Após a definição das classes de uso, o próximo passou consistiu na classificação automática da imagem para a determinação do uso do solo do município. A classificação empregada foi do tipo supervisionada, que consiste na seleção de amostras de treinamento (conjuntos de pixels) representativas de cada classe de uso do solo.

\section{Resultados e Discussões}

A partir dos mapas de uso e ocupação do solo dos anos de 1986 e 2009 e do cruzamento com as áreas de preservação permanente previamente delimitadas, foi possível realizar uma análise comparativa das mudanças espaciais e temporais no uso e ocupação das APP's (Tabela 1). 
Tabela 1 - Uso e Ocupação do Solo nas APP's do município de Butiá nos anos de 1986 e 2009

\begin{tabular}{|c|c|c|c|c|}
\hline $\begin{array}{c}\text { Classe de Uso e Ocupação } \\
\text { do Solo }\end{array}$ & $\begin{array}{c}\text { Uso e Ocupação do } \\
\text { Solo das APP's } \\
(1986)\end{array}$ & $\begin{array}{c}\text { Uso e Ocupação do } \\
\text { Solo das APP's } \\
(1986)\end{array}$ & $\begin{array}{c}\text { Uso e Ocupação do } \\
\text { Solo das APP's } \\
(2009)\end{array}$ & $\begin{array}{c}\text { Uso e Ocupação do } \\
\text { Solo das APP's } \\
(2009) \\
\end{array}$ \\
\hline & Área $\left(\mathrm{Km}^{2}\right)$ & Área $(\%)$ & Área $\left(\mathrm{Km}^{2}\right)$ & Área $(\%)$ \\
\hline Água & 9,08010 & 08 & 7,4682 & 6 \\
\hline $\begin{array}{c}\text { Campo, pastagem e cultura } \\
\text { anual }\end{array}$ & 57,1554 & 49 & 47,5173 & 41 \\
\hline Floresta Nativa & 29,0214 & 25 & 20,5708 & 18 \\
\hline Floresta Plantada & 8,3025 & 07 & 27,8042 & 23 \\
\hline Solo Exposto/Área Urbana & 13,7412 & 11 & 13,9401 & 12 \\
\hline Área Total & 117,3006 & $100 \%$ & 117,3006 & $100 \%$ \\
\hline
\end{tabular}

Fonte: $\mathrm{O}$ autor.

Observou-se que o uso conflitante nas APP's foi significativo principalmente pelo avanço das áreas reflorestadas sobre estes espaços, como pode ser verificado na (figura 3), que mostra a ocupação das APP's na região sul do município. Essa região foi a que apresentou maior aumento das áreas de reflorestamento, conforme pode ser verificado nos mapas de uso e ocupação do município nos anos de 1986 e 2009 (figura 4 e 5, respectivamente). 


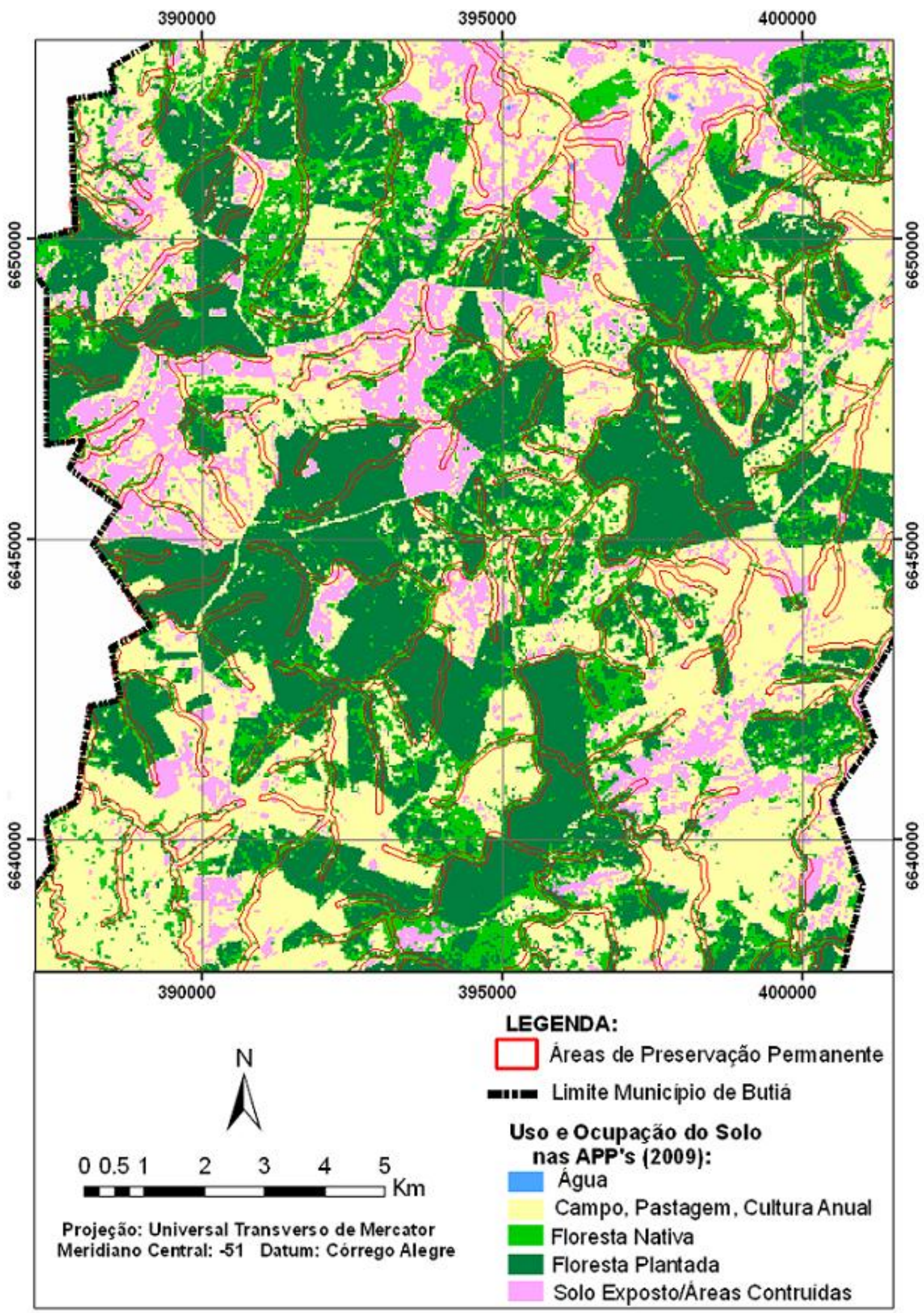

Figura 3 - Mapa da região sul do município, com o uso e ocupação das APP's no ano de 2009 Fonte: o autor. 


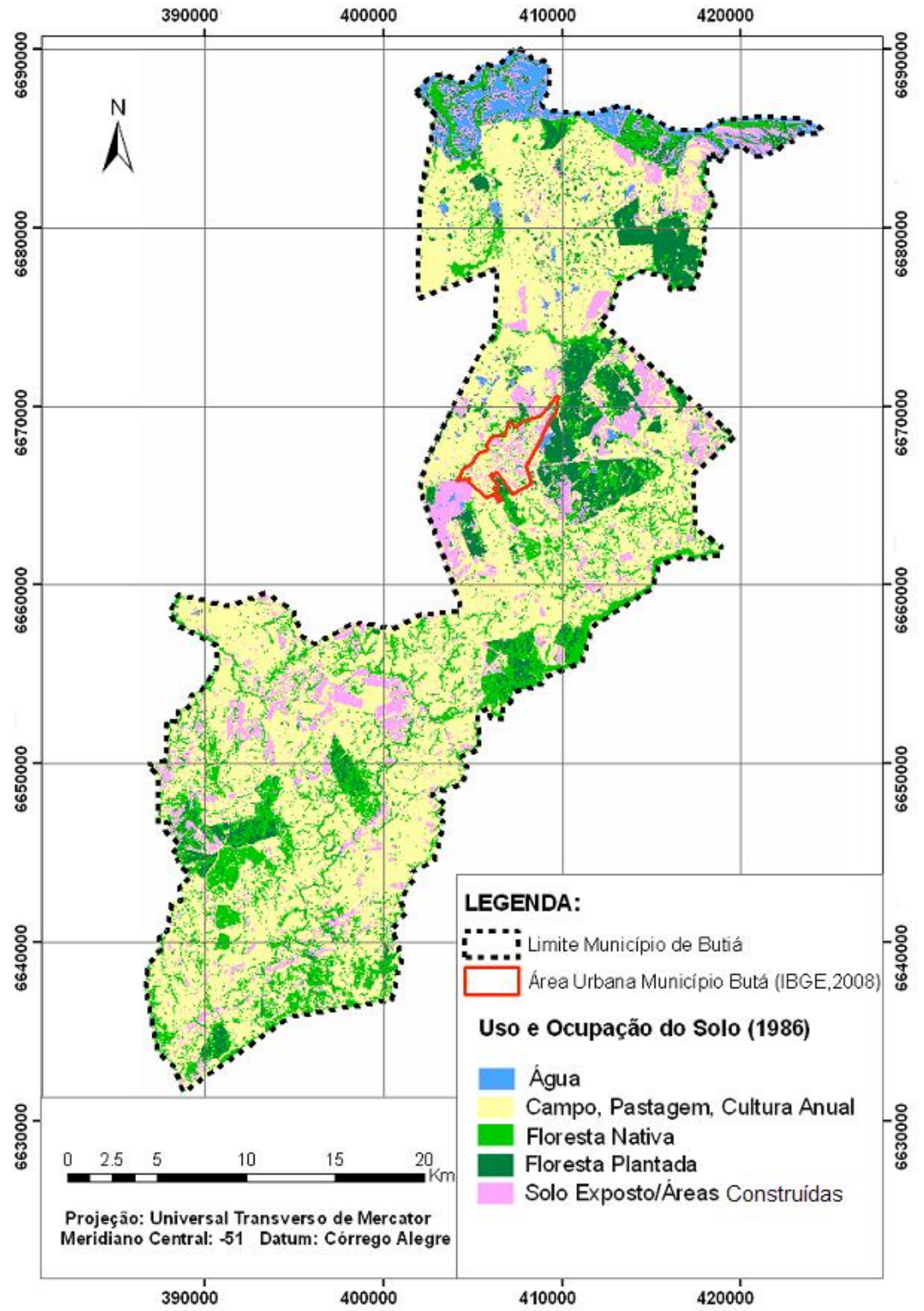

Figura 4 - Mapa do uso e ocupação do solo do município de Butiá no Ano de 1986. Fonte: o autor. 


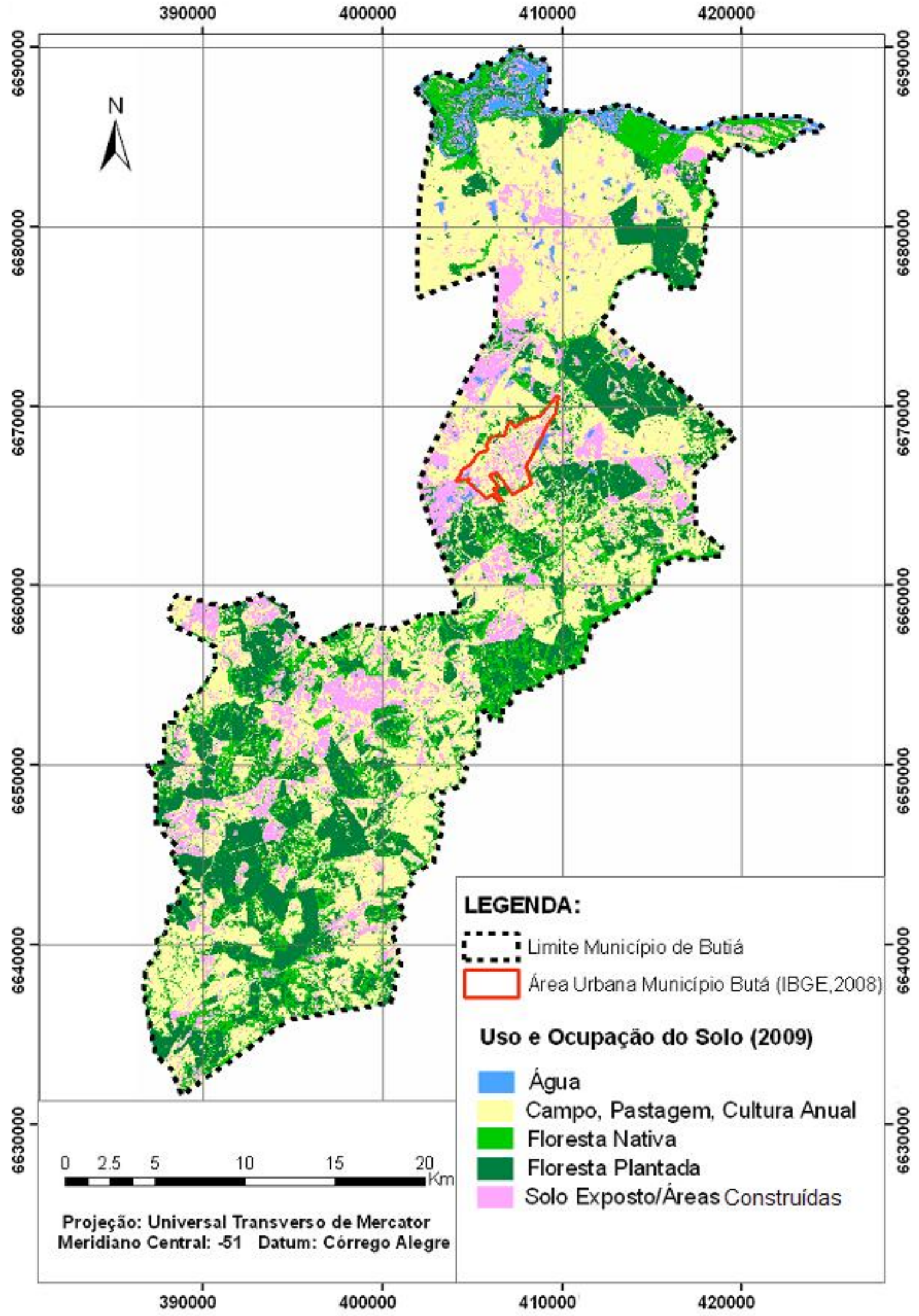

Figura 5 - Mapa do uso e ocupação do solo do município de Butiá no Ano de 2009. Fonte: o autor. 
Este aumento significativo da área ocupada por reflorestamento de espécies exóticas pode ser explicado pelo fato de que o município de Butiá está inserido na metade sul do estado. Nos últimos anos, diversos programas de incentivo às atividades de silvicultura vêm sendo implantados com o objetivo de recuperar economicamente essa região.

O desenvolvimento dessa região, no decorrer da evolução histórica, baseou-se nas atividades de pecuária e posteriormente na lavoura de arroz. A metade sul é caracterizada por uma estrutura fundiária de concentração de terras. Essa estrutura é resultante do sistema de sesmarias instituídas no período colonial, refletindo em outros aspectos que caracterizam a sociedade local até o presente, como a concentração da renda, os centros urbanos esparsos, a reduzida densidade da população rural e o predomínio da pecuária (ALONSO, 1994).

Assim, o desenvolvimento econômico da metade sul é marcado por uma estagnação econômica, contribuindo com uma parcela pouco significativa na produção total do estado. Nesse contexto, o governo do Estado, a fim de promover o desenvolvimento econômico regional, implantou políticas objetivando a mudança no perfil produtivo na região, com incentivo às atividades de silvicultura.

Dessa forma, grandes empresas do setor de celulose, como Votorantim, Aracruz e Estora Enso, fizeram investimentos na região, adquirindo grandes extensões de terras para o desenvolvimento de florestamento e reflorestamento de espécies como o eucalipto e acácianegra.

\section{Considerações Finais}

Diante dos resultados apresentados, observou-se uma expressiva alteração no uso e ocupação do solo no município de Butiá, entre o período compreendido entre os anos de 1986 e 2009. A principal mudança se deu pelo aumento das áreas destinadas ao reflorestamento de espécies exóticas, como o eucalipto e acácia-negra, apresentadas na classe de floresta plantada no mapa elaborado. As áreas destinadas ao cultivo destas espécies quase triplicaram no período de tempo analisado. Esse avanço se deu em todo o território, inclusive nas áreas de preservação permanente que foram delimitadas no estudo, o que causou a descaracterização da vegetação natural nestes espaços.

Neste sentido, verifica-se um grande desafio para a administração pública do município, pois se faz necessária a adoção de medidas que viabilizem as atividades econômicas ao mesmo tempo em que respeitem o cumprimento da legislação ambiental, a fim 
de promover o desenvolvimento econômico em harmonia com o meio ambiente. Sendo assim, as informações sobre o uso e a ocupação do solo tornam-se fator importante na implementação de projetos de planejamento e monitoramento do território, pois permitem mapear as formas menos adequadas e poucos conservacionistas dos recursos naturais.

As ferramentas de Sistemas de Informações Geográficas mostraram-se plenamente satisfatórias para o desenvolvimento desta pesquisa, pois por meio delas foi possível a integração, a manipulação, o cruzamento e a quantificação de dados espaciais necessários para atingir o objetivo proposto. Assim, ressalta-se a importância do uso dos SIG's por organizadores nas diferentes esferas administrativas, tendo em vista, que estas ferramentas proporcionam informações confiáveis e precisas sobre o espaço contribuindo para atividades de planejamento e processos de tomada de decisão.

\section{Bibliografia}

ALONSO, José Antônio Fialho. Evolução das desigualdades inter - regionais de renda interna no Rio Grande do Sul: 1939 - 70. Fundação de Economia e Estatística Siegfried Emanuel Heuser. Porto Alegre, n.9, 1986.

BRASIL, Código Florestal brasileiro, Lei 4.771 de 15/09/1965 - Disponível em: $<w w w . p l a n a l t o . g o v . b r / c c i v i l \_03 / L E I S>$. Acessado em 07/6/2009.

BACHEGA, C.C.F.; FILHO, A.C.P.; TIVIROLI, V.A.; MIRANDA, C.S.; ANACHE, J.A.A. Análise multitemporal da cobertura do solo na bacia do Rio Negro, MS. Anais XIV Simpósio Brasileiro de Sensoriamento Remoto, Natal, Brasil, 25-30 abril 2009, INPE, p. 1253-1259.

CARLOS, A. F. A.. A cidade. $8^{\circ}$ ed. São Paulo-SP: Contexto, 2007. v. 1.98 p.

CARVALHO, M. S.; PINA, M. F.; SANTOS, S. M. Conceitos básicos de sistemas de informações geográficas aplicados à saúde. Brasília: Organização Panamericana de Saúde/Ministério da Saúde, 2000, 124 p.

CENTENO, J. A. S. Sensoriamento Remoto e Processamento de Imagens Digitais. Departamento de Geomática - UFPR. Curitiba-PR. 210 p. 2003.

GIOTTO, E. Aplicabilidade de Imagens RBV do LANDSAT 3 em levantamento do uso da terra no município de Tapera - RS. 1981, 66p. Dissertação (Mestrado em Engenharia Agrícola) - Universidade Federal de Santa Maria,Santa Maria.

IBGE. Censo Demográfico. Disponível em: <http://www.ibge.gov.br/cidadesat>. Acesso em 07/6/2009. 
INPE, Instituto Nacional de Pesquisas Espaciais - Ministério da Ciência e Tecnologia, disponível em http://www.inpe.br/, diversos acessos em Outubro/2009.

MOREIRA, M.A.; Fundamentos de sensoriamento remoto e metodologia de aplicação. $3^{\circ}$ Ed. atual. Ampl. - Viçosa: Ed. UFV, 2005.

MOURA, A. C. Geprocessamento na gestão e planejamento urbano - 2 ed. - Belo Horizonte: Ed. da autora, 2003. 294p.

RESOLUÇÃO $\mathbf{N}^{\mathbf{0}}$ 303, DE 20 DE MARÇO DE 2002, disponível em: $<w w w . m m a . g o v . b r / p o r t / c o n a m a / r e s\rangle$. Acesso em 07/6/2009.

Rio Grande do Sul. Secretaria Estadual do Meio Ambiente. Diretrizes ambientais para a restauração de matas ciliares/ Departamento de Áreas Protegidas. Porto Alegre, 2007. 33p.

SAMPAIO, D.M. Análise Ambiental do Conflito das Áreas de Preservação Permanente e uso do Solo na Bacia hidrográfica de Vargem das Flores, utilizando ambientes de Geoprocessamento. Monografia (Especialização em Geoprocessamento). UFMG, 2007, 53p.

Silva, A.B. Sistemas de Informações Geo-referenciadas: conceitos e fundamentos. Campinas, SP: Ed. Unicamp, 1999. 235p. 